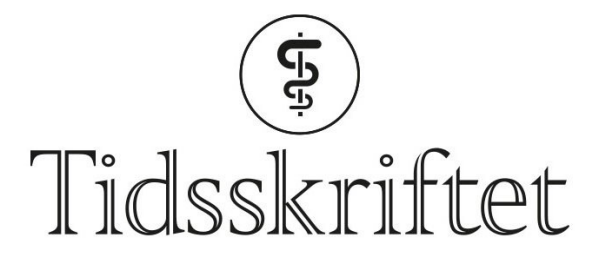

DEN NORSKE LEGEFORENING

\title{
Epilepsiomsorgens start i Norge
}

I TIDLIGERE TIDER

\section{OLIVER HENNING}

E-post: olihen@ous-hf.no

Oliver Henning er nevrolog, psykiater og overlege ved Spesialsykehuset for epilepsi. Forfatteren har fylt ut ICMJE-skjemaet og oppgir ingen interessekonflikter.

\section{KARL O. NAKKEN}

Karl O. Nakken er pensjonert nevrolog. Han var i mange år medisinsk ansvarlig ved Spesialsykehuset for epilepsi.

Forfatteren har fylt ut ICMJE-skjemaet og oppgir ingen interessekonflikter.

I 1912 ble det etablert en epilepsikoloni i Bærum inspirert av lignende kolonier i andre land. Trang økonomi og begrensede behandlingsmuligheter preget de første årene.

I kjelleren på Spesialsykehuset for epilepsi i Bærum kom vi nylig over flere historiske dokumenter. Disse gir et innblikk i de første årene av det som kan kalles en organisert epilepsiomsorg i Norge, og omfatter sykeprotokoller for perioden 1913-20, fem kopibøker for perioden 1905-23 og en regningsbok for perioden 1905-20 (figur 1).

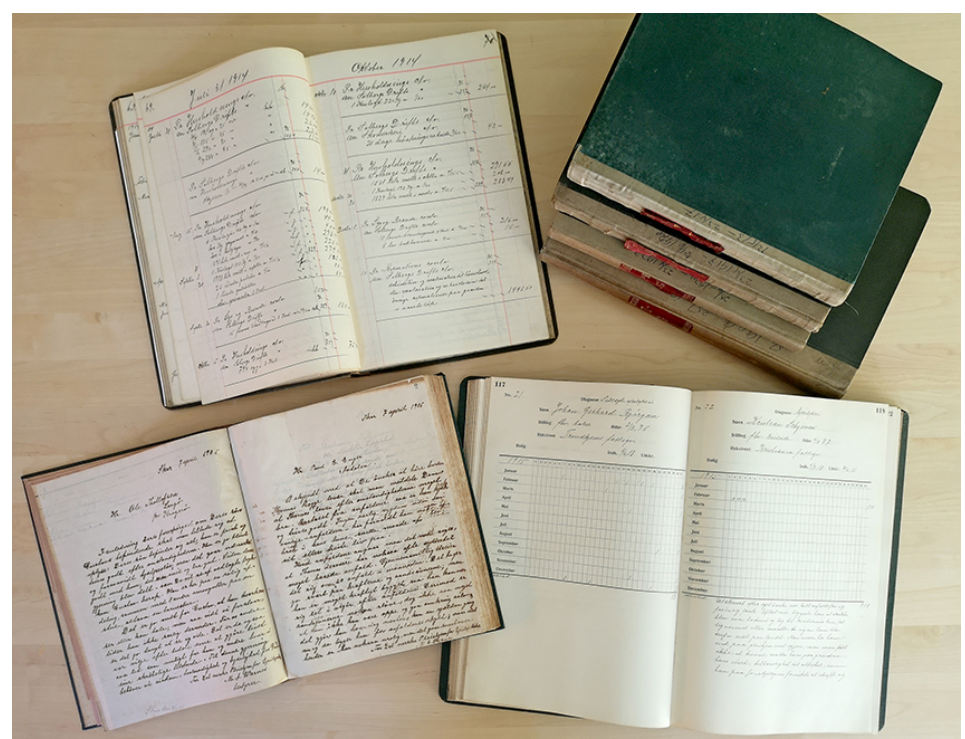

Figur 1 Bøker som ble funnet $i$ kjelleren ved Spesialsykehuset for epilepsi, og som har gitt et innblikk $i$ livet ved institusjonen de første årene (1913-20). Foto: Oliver Henning

Før 1920 hadde ikke pasientene egne sykejournaler slik vi kjenner det i dag. Kopibøkene og regningsboken ga informasjon hovedsakelig om den daglige driften ved kolonien, mens sykeprotokollene og anfallskalenderne ga oss en del kliniske opplysninger om pasientene som var innlagt på den tiden. 


\section{Etablering av epilepsikolonier}

På begynnelsen av 18oo-tallet ble det i mange land opprettet asyler for mennesker som ikke klarte seg selv, hovedsakelig dem med psykiske lidelser, epilepsi eller utviklingshemning (1). Man mente at samfunnet måtte skjermes fra slike personer. Folk med epilepsi som ikke havnet på asyl, hadde som regel store problemer med å klare seg i samfunnet. I det regulære skoleverket var barn med epilepsi utelukket, og for voksne var det vanskelig å få seg lønnet arbeid. I byene bodde mange i fattiggårder, og på landet gikk mange på legd mellom gårdene. Legdsystemet var en plikt bøndene hadde overfor fattigvesenet, og alle måtte bidra. Personen som gikk på legd, var gjerne på samme gård ett år av gangen.

I siste halvdel av 18oo-tallet ble det i enkelte europeiske land opprettet epilepsikolonier, blant annet i Tyskland og England $(1,2)$. Intensjonen var å lage små selvstendige samfunn for personer med epilepsi på utsiden av storsamfunnet. Koloniene var som regel plassert for seg selv ute på landet, og de fleste kom i stand på initiativ av filantroper som var knyttet til en kristenhumanistisk bevegelse med utspring i Tyskland.

\section{Pioneren Ludvig Waale}

Inspirert av et besøk ved epilepsikolonien Bethel i Bielefeld i Tyskland etablerte diakon Ludvig Waale (1861-1932) i 1895 en liten epilepsiinstitusjon i Kristiania. Den lå først på Lindern, ble litt senere flyttet til Skar i Maridalen og dernest til Sandaker (3). I sitt pionerarbeid møtte Waale mye motgang. En vanlig oppfatning var at folk med en så skremmende sykdom som epilepsi hørte hjemme på asylene.

Intensjonen var å lage små selvstendige samfunn for personer med epilepsi på utsiden av storsamfunnet

Tidlig på 19oo-tallet tok forstander Hartvig Halvorsen (1854-1910) i Diakonhjemmets styre til orde for at diakonene burde ha epilepsiomsorg på sitt program. I 1904 ble man derfor enig med Waale om at hans pleiehjem skulle sortere under Diakonhjemmet. Pleiehjemmet ble fra 1. januar 1905 hetende Det norske pleiehjem for epileptikere, og diakon Mikal Antonius Wærnes (1865-dødsår ukjent) ble utnevnt til bestyrer. Pasienter i alle aldre, også barn ned til 5-6 år, ble tatt imot. Det fremgår av regningsboken at det offentlige i 1907 betalte 420-445 kroner per pasient per år, mens privatpersoner måtte betale 480-60o kroner.

\section{Solberg gård blir epilepsikoloni}

Dels fordi pleiehjemmet hadde for få plasser i forhold til behovet, og dels på grunn av naboklager, valgte Diakonforbundet i 1912 å kjøpe Solberg gård, som lå sentralt i Bærum, og flytte pleiehjemmet dit (figur 2). Til gården hørte 500 mål dyrket mark, og prisen var 63000 kroner. Institusjonen ble bygget opp etter mønster fra epilepsikoloniene i andre europeiske land, og driften kom i gang våren 1913. 


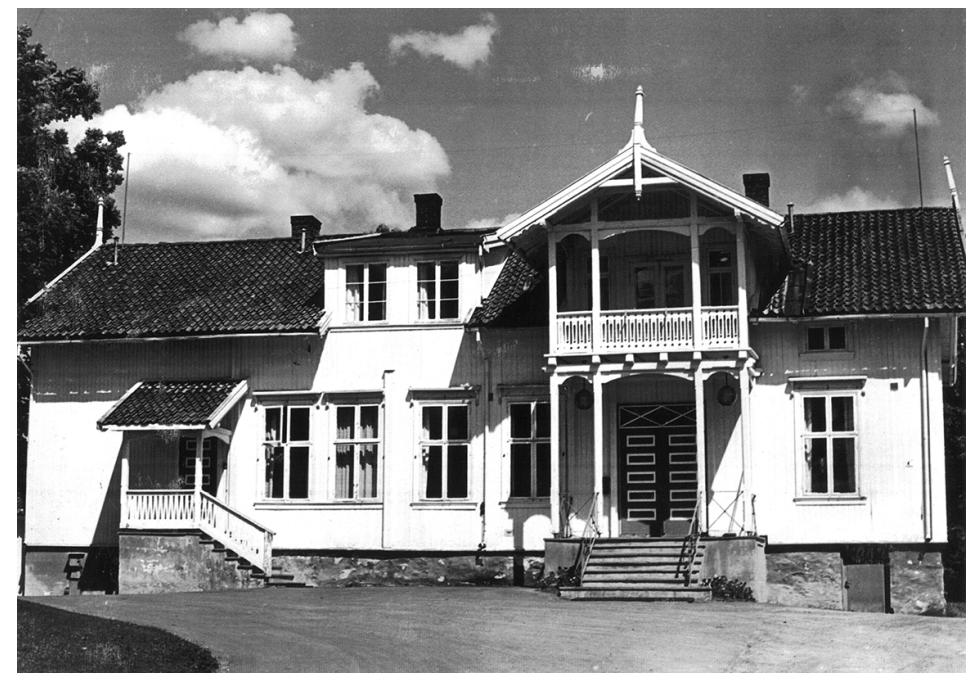

Figur 2 Solberg gård. Våningshuset er i dag revet og erstattet av et laboratoriebygg. Bilde fra ca. 1965. Foto: ukjent, tilhører Spesialsykehuset for epilepsi

Pasienter fra hele landet ble henvist til Solberg gård. Rundt 80 \% av innleggelsene ble finansiert av det offentlige, hovedsakelig av det lokale fattigvesenet. De øvrige $20 \%$ ble betalt av pårørende. Av og til skortet det på betalingsviljen, kanskje også evnen. Om en pasient som var innlagt fra februar 1913 til august 1914, heter det: «Faderen vilde ha ham hjem. Kunde ikke betale for ham i den dyretid.» Om en annen pasient som var innlagt et halvt år i 1914, står det: «flyttet hjem til moren igjen da Larvik fattigvesen ikke vilde betale længre for ham.»

Trang økonomi var et stort problem de første årene. Professor Christopher Blom Leegaard (1851-1921) ved Rikshospitalet, som var den første tilsynslegen, fikk i årene 1905-20 en årslønn på 500 kroner. Da Peter Christen Barth (1872-1942) overtok i 1920, ble årslønnen justert opp til 6 oo kroner.

Ifølge Wærnes' kostholdsberegning fra 1909 fikk man betalt 1,21 kroner per pasient per døgn, mens kostnadene var 1,45 kroner, dvs. en differanse på o,24 kroner. I 1919 var denne differansen $ø$ kt til 2,16 kroner. Det var også andre bekymringer: «... man for næste vinter maa gaa til indkjøp av ved. Skogen er nu stadig blit tyndet saa stærkt at det ikke kan lade sig gjøre at hugge mere ....

Wærnes skriver et annet sted: «Alle er nok enig i det, at stelle vel om de syke maa man ikke bare tilstrebe men også virkeliggjøre; men her er det økonomien griper ind ofte paa en for de syke uheldig maate. Hjertelaget hos betjeningen kan slette over manglerne, det er sandt, men ....

Antall pasienter per år varierte, fra 50 i 1905 til 82 i 1917, mens årlige liggedøgn varierte fra rundt 13 ooo i 1908 til rundt 23 ooo i 1917.

\section{Hyppige anfall og høy mortalitet}

På epilepsikolonien førte man anfallskalendere for alle innlagte pasienter (figur 3). I perioden 1908-19 ble det etter våre anslag i gjennomsnitt registrert o,45 anfall per pasient per døgn. Enkelte hadde svært hyppige anfall. Eksempelvis ble det hos en mannlig pasient registrert 2526 anfall i august 1915. Anfallene ble ikke subklassifisert, slik vi gjør i dag. Men antakeligvis var de fleste kalenderregistrerte anfallene hovedsakelig store krampeanfall, det vil si anfall av tonisk-klonisk type. 
17
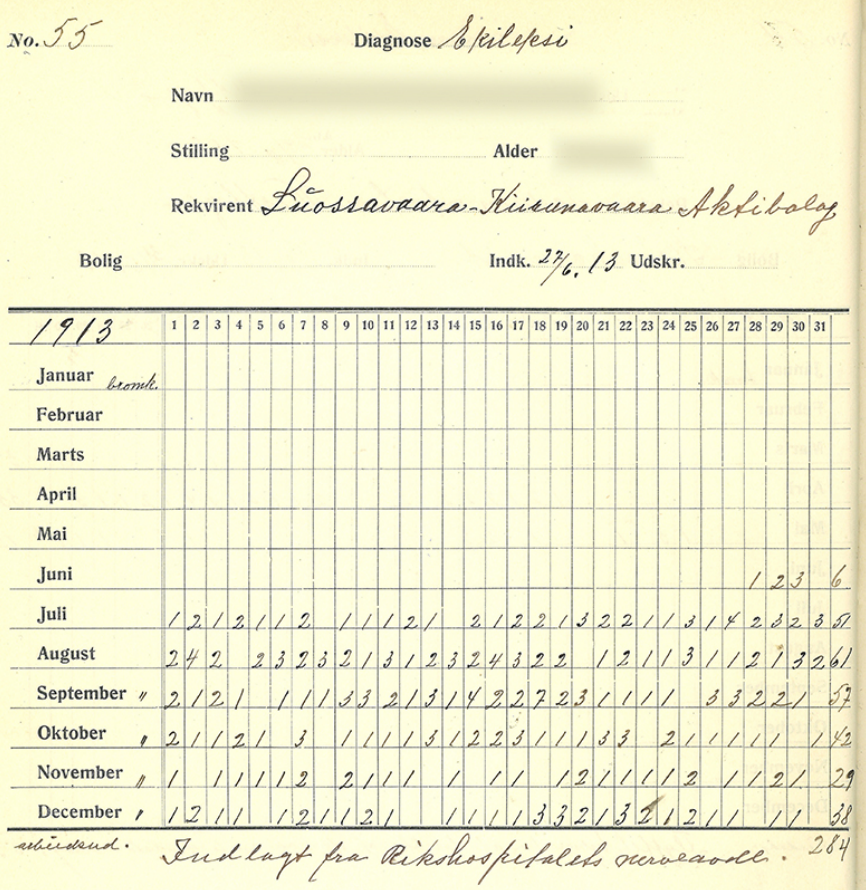

Figur 3 Anfallskalender fra en pasient som var innlagt $i$ 1913. Foto: Oliver Henning

I perioden 1912-19 var det i gjennomsnitt 8,5 årlige dødsfall ved kolonien (4-24 dødsfall). Det fantes på den tiden ingen anfallskuperende behandling, og mange døde i status epilepticus (figur 4). At tallet på døde var særlig høyt i 1918, skyldes hovedsakelig spanskesyken.

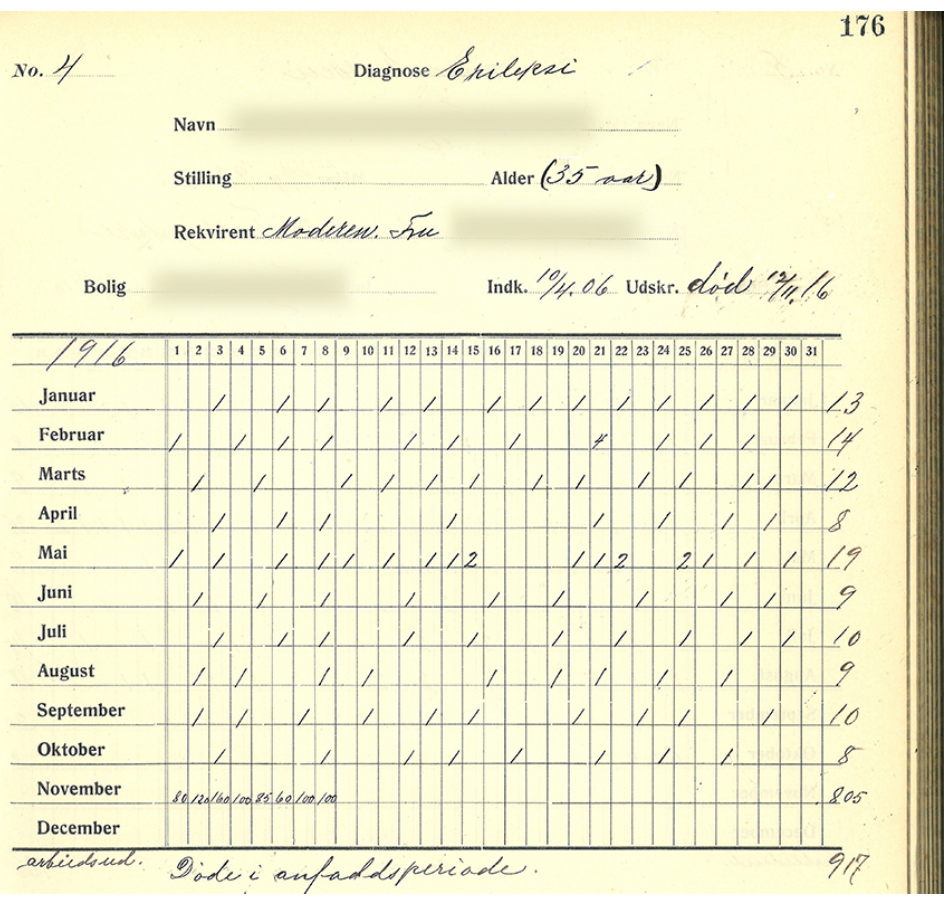

Figur 4 Anfallskalender for en pasient som 11916 døde i status epilepticus. Foto: Oliver Henning

I et brev til pårørende som hadde mistet sin sønn, skriver Wærnes: «Min mening er at det var bedst for ham, som det gik. Et længre liv i den sindsforvirring og uro vilde kun voldt ham selv og familien større smærte end denne forholdsvise rolige afslutning paa et liv i haard kamp mod en uhelbredelig og stærkt nedbrydende sygdom.»

\section{Hvilken behandling fikk pasientene?}

Pasientene fikk behandling med bromsalter, hovedsakelig kaliumbromid (Borat). Bromsalter hadde en viss anfallsdempende effekt, men av og til får vi inntrykk av at bivirkningene var verre enn selve epilepsien. Bivirkningene, kalt bromisme, ytret seg som tretthet, mental treghet, apati, synsforstyrrelser, kvalme, sikling, ustøhet og alvorlig akne, 
pustler eller sår, særlig i ansiktet og nakken (4). Bromakne i ansiktet ble kalt facies epileptica. Psykiatriske bivirkninger i form av irritabilitet, uhemmet og utagerende atferd, depresjon, hallusinasjoner og noen ganger schizofreniliknende psykoser var heller ikke uvanlig. Mange av pasientene beskrives da også som dypt sløvet. Om en kvinne innlagt i 1917 står det: «Ved innlæggelsen hadde patienten store saar paa armer og ben ... utslet angivelig efter bromcalium som har vært brugt længe.»

På grunn av en prekær økonomisk situasjon fremsetter Wærnes i 1919 tre mulige løsninger for kolonien

Fenobarbitals anfallsdempende egenskaper ble oppdaget av den tyske legen Alfred Hauptmann i 1912 (5), men dette midlet kom ikke i klinisk bruk i Norge før etter 1920.

\section{Epilepsi pluss}

I tillegg til en alvorlig epilepsi hadde de fleste pasientene problemer av kognitiv, psykiatrisk og/eller atferdsmessig art, det vi kaller epilepsi pluss (6). For oss har det vært vanskelig å tolke om pasientenes atferdsavvik var knyttet til epilepsiårsaken, ikke-erkjente fokale epileptiske anfall, postiktale psykoser, bivirkninger av behandlingen, komorbiditet eller andre forhold. I et brev 6. april 1910, stilet til Amtmanden i Kristians Amt, skriver Wærnes blant annet: «... patienten hadde 362 anfald i 1909, bromkalium ble brugt hele aaret. Patientens sansevner er sløvet betydelig. Periodisk indtræder sindsforstyrrelser hvorunder patienten bliver meget urolig, til dels voldsom, saa han maa isoleres.)

Forbigående psykoselignende tilstander blir beskrevet hos flere pasienter, noe vi tolker som sannsynlige postiktale psykoser. Om en pasient skrives det i 19o6: «Lørdagen før jul ble han rent tullet i hode; han begynte med at ikke ville spise, fikk saa hallucinationer. Han måtte da holdes i sengen ... Nu for 2 dager siden er han adskillig bedre, saa han spiser og kan svare paa tiltale og spurgte efter far.»

Om en annen pasient som var innlagt fire måneder i 1915, heter det: «Utskrevet paa grund av uro og voldsomhet, det vedvarte næsten stadig. Patienten maatte holdes bundet den sidste tid, da han skadet sig selv.»

\section{Staten overtar i 1920}

På grunn av en prekær økonomisk situasjon fremsetter Wærnes i 1919 tre mulige løsninger for kolonien: «prisforhøielse av pleiebidragene», «statens overtagelse av hele anstalten» og «midlertidig nedlæggelse av pleiehjemmet, gaardens drift fortsættes».

En søknad om prisforhøyelse av pleiebidragene ble sendt til helsemyndighetene, men søknaden ble avslått. I 1920 så diakonene ingen annen utvei enn å overdra hele kolonien vederlagsfritt til staten. Forutsetningen var at eiendommen skulle brukes «til beste for epileptikere». Det første de statlige eierne gjorde, var å forhøye døgnprisen.

De neste 100 årene ble kolonien gjenstand for omfattende modernisering. I dag heter institusjonen på tidligere Solberg gård (figur 5) Spesialsykehuset for epilepsi og sorterer under Oslo universitetssykehus. Spesialsykehuset er landets eneste sykehus for pasienter med alvorlig og vanskelig kontrollerbar epilepsi. Med sin historie er det et monument over det siste hundreårets rivende utvikling innen epilepsiomsorgen. 


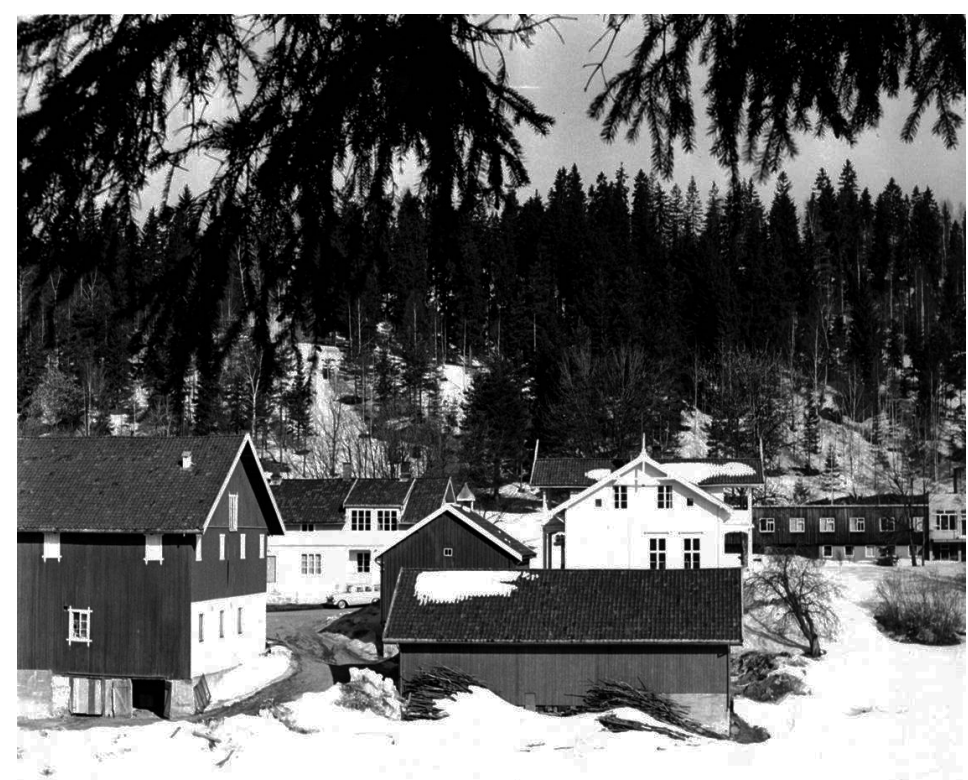

Figur 5 Epilepsisenteret på Solberg gård i Bcrum i 196o-årene. Foto: ukjent, tilhører Spesialsykehuset for epilepsi

\section{LITTERATUR:}

1. Schmidt D, Shorvon S. The end of epilepsy? A history of the modern era of epilepsy 1860-2010. Oxford: Oxford University Press, 2016: 22.

2. Grewe P, Bien CG. 15oth anniversary of the Bethel epilepsy center in Germany: An important milestone in the evolution of epilepsy care. Seizure 2017; 53: 110-3. [PubMed][CrossRef]

3. Nakken KO. Fra epilepsikoloni til spesialsykehus. Glimt fra epilepsi-institusjonen ved Solberg gård gjennom 100 år. Unikom Grafisk, 2006:11.

4. Shorvon S, Shepherd L. The beginning of the end of the falling sickness. Epilepsy and its treatment in London 1860-1910. Bristol: Burleigh Portishead Ltd., 2012: 48-50.

5. Hauptmann A. Luminal bei Epilepsie. Munch Med Wochenschr 1912; 59:1907-12.

6. Coppola A, Cellini E, Stamberger H et al. Diagnostic implications of genetic copy number variation in epilepsy plus. Epilepsia 2019; 60: 689-706. [PubMed][CrossRef]

Publisert: 22. januar 2021. Tidsskr Nor Legeforen. DOI: 10.4045/tidsskr.20.0731

(C) Tidsskrift for Den norske legeforening 2020. Lastet ned fra tidsskriftet.no 